\title{
Avaliação in vitro da atividade antimicrobiana do extrato da Lippia sidoides Cham. sobre isolados biológicos de Staphylococcus aureus
}

\begin{abstract}
SILVA, V.A. ${ }^{1 *}$; FREITAS, A.F.R. ${ }^{1}$ PEREIRA, M.S.V. ${ }^{1}$; SIQUEIRA JÚNIOR, J.P. ${ }^{\text {; }}$ PEREIRA, A.V. ${ }^{2}$; HIGINO, J.S. ${ }^{3}$ 'Universidade Federal da Paraíba, Departamento de Biologia Molecular, Campus I, Cidade Universitária, CEP: 58051-900, João Pessoa-Brasil *viviane.biologia@hotmail.com/ nanda.biologia@hotmail.com/ vieirapereira@uol.com.br 2Universidade Federal de Campina Grande, Avenida Universitária, Bairro Jatobá, s/n, CEP:58700-910, Patos-Brasil andreiavet@hotmail.com³ Universidade Federal de Pernambuco, Departamento de Farmácia, Avenida Prof. Artur de Sá, s/n, CDU, CEP: 50670-901, Recife-Brasil
\end{abstract}

\begin{abstract}
RESUMO: Staphylococus aureus apresenta-se como microrganismo patogênico clássico sendo comumente reconhecido como agente etiológico de infecções hospitalares e comunitárias. Através do conhecimento das propriedades biológicas da Lippia sidoides Cham., conhecida como alecrimpimenta, esta pesquisa teve como objetivo avaliar a atividade antimicrobiana in vitro do extrato metanólico desta planta em inibir o crescimento de isolados biológicos de $S$. aureus de origem humana hospitalar. Utilizou-se o método de difusão em Agar Muller Hinton para se determinar a Concentração Inibitória Mínima do extrato. A atividade anti-estafilococica do extrato da Lippia sidoides Cham. foi observada-pela formação de halos de inibição do crescimento bacteriano ( 9 a $27 \mathrm{~mm}$ ), todas as amostras ensaiadas mostraram-se sensíveis à ação do extrato da Lippia sidoides Cham. até a diluição de 1:16 $\left(0,053 \mathrm{~g} \mathrm{~mL}^{-1}\right)$. Nas condições desse estudo, esses resultados mostram promissora atividade antibacteriana do extrato de Lippia sidoides Cham.
\end{abstract}

Palavras-chave: alecrim-pimenta, atividade antibacteriana, infecção nosocomial, Lippia sidoides, Staphylococcus aureus

\begin{abstract}
In vitro evaluation of the antimicrobial activity of Lippia sidoides Cham. extract on biological isolates of Staphylococcus aureus. Staphylococcus aureus is a classic pathogenic microorganism commonly recognized as etiological agent of community and nosocomial infections. Considering the knowledge of Lippia sidoides Cham. (Alecrim-pimenta) biological properties, this study aimed to evaluate in vitro the antimicrobial activity of the extract from this plant in inhibiting the growth of $S$. aureus from hospitalized humans. The Agar Mueller-Hinton diffusion method was used to determine the Minimum Inhibition Concentration of the extract. The anti-Staphylococcus aureus activity of Lippia sidoides Cham. extract was noted by the large growth inhibition zones (9 to $27 \mathrm{~mm}$ ); all tested samples were sensitive to the action of Lippia sidoides Cham. extract until the dilution of 1:16 $\left(0.053 \mathrm{~g} \mathrm{~mL}^{-1}\right)$. Under the conditions adopted in the present study, these results show the promising anti-staphylococcal property of Lippia sidoides Cham. extract.
\end{abstract}

Key words: "alecrim-pimenta", antimicrobial activity, nosocomial infection, Lippia sidoides, Staphylococcus aureus

\section{INTRODUÇÃO}

Bactérias do gênero Staphylococcus, família Micrococcaceae, são cocos gram-positivos com diâmetros médios entre 0,5 e 1,5 $\mu \mathrm{m}$, imóveis, não esporulado e geralmente não capsulado; isolados aos pares, em cadeias curtas, ou agrupados irregularmente com aspectos semelhantes a cachos de uva e catalase positivos (Tortora et al., 2003; Harvey \& Gilmour, 2005;

\section{Cassetari et al., 2005).}

Atualmente, o gênero Staphylococcus possui 33 espécies, sendo que 17 delas podem ser isoladas de amostras biológicas humanas. A espécie mais importante do gênero é Staphylococcus aureus (Santos et al., 2007). Patógenos da microbiota normal da pele e das vias respiratórias podem causar

Recebido para publicação em 19/02/2009

Aceito para publicação em 14/05/2010

Rev. Bras. PI. Med., Botucatu, v.12, n.4, p.452-455, 2010. 
infecções, com frequência associadas a dispositivos e aparelhos implantados, principalmente em pacientes imunocomprometidos, muito jovens ou idosos (Brooks et al., 2000). Segundo Vandenbergh \& Verbrugh (1999), o portador dessa bactéria exerce papel importante na epidemiologia e na patogênese de infecção, sendo o maior fator de risco para o desenvolvimento de infecções hospitalares adquiridas na comunidade.

Para Metam et al. (2005), cerca de 50 a 87\% das infecções hospitalares, tem Staphylococcus como agente responsável, sendo que em 16 a 43\% dos casos os pacientes evoluem para óbito em função do amplo espectro de resistências desses microrganismos aos antimicrobianos.

O controle de disseminação de espécies de Staphylococcus spp. resistentes a antimicrobianos é desafio. Nos últimos anos, a resistência de microrganismos patogênicos a múltiplas drogas tem aumentado devido ao uso indiscriminado de antimicrobianos, utilizados no tratamento de doenças infecciosas. Essa situação vem despertando o interesse dos cientistas na busca de novas drogas. As plantas constituem em uma excelente fonte de substâncias para novas drogas antimicrobianas, tendo em vista que a diversidade molecular dos produtos naturais é muito superior àquela derivada dos processos de síntese química (Novais et al., 2003).

Lippia sidoides Cham., nativa do Nordeste do Brasil e no Norte de Minas Gerais, pertence à família Verbenaceae é conhecida popularmente como alecrimpimenta ou estrepa-cavalo (Martins et al., 2000). É um grande arbusto caducifólio, ereto, muito ramificado e quebradiço, possui cerca de 2 a $3 \mathrm{~m}$ de altura, os frutos são do tipo aquênio, muito pequenos e as sementes raramente germinam (Lorenzi \& Matos, 2002).

Nas folhas da Lippia sidoides Cham. encontram-se até $4,5 \%$ de óleo essencial rico em timol, principio ativo responsável pelo seu cheiro característico (Matos, 2002). São geralmente utilizadas para tratamento de acne, ferimentos, infecções da pele e do couro cabeludo. Ainfusão tem sido utilizada popularmente em inalações, rinite alérgica e no tratamento das infecções da boca, da garganta e da vagina (Matos \& Oliveira, 1998).

O extrato da Lippia sidoides Cham. apresenta forte ação contra fungos, bactérias e outros organismos, tais como, S.aureus, Streptococcus mutans responsável pela cárie dentária, Corynebacterium xerosis que causa mau cheiro nas axilas e nos pés, Candida albicans encontrada nas infecções da boca e no corrimento vaginal, Trichophytum rubrum e Trichiphytun interdigitale agentes de micoses na pele. Apresenta ação moluscida contra o caramujo Biomphalaria glabra, hospedeiro da esquistossomose e ação larvicida contra o mosquito Aedes aegypti, transmissor da dengue (Lemos et al., 1990; Lacoste et al., 1996; Matos, 2000).
Sendo assim, o presente trabalho tem como objetivo avaliar a atividade antimicrobiana do extrato da Lippia sidoides Cham. sobre isolados de S.aureus de origem humana hospitalar.

\section{MATERIAL E MÉTODO}

\section{Material Botânico}

Foram utilizadas folhas de Lippia sidoides Cham. (alecrim-pimenta) da família Verbenaceae, cultivadas no Horto de plantas medicinais do Laboratório de Tecnologia Farmacêuticas (LTF) da Universidade Federal da Paraíba. As folhas foram coletadas no inicio da floração e secas em estufa a $40^{\circ} \mathrm{C}$.

\section{Obtenção do Extrato}

Para a obtenção do extrato foi empregado o método de lixiviação em fluxo contínuo à temperatura ambiente com solução extratora de álcool metanol a $80 \% \mathrm{v} / \mathrm{v}$ renovado constantemente por um período de 24 horas, obtendo-se $500 \mathrm{~mL}$ de concentrado. A extração foi realizada no Laboratório de Tecnologia Farmacêuticas do Departamento de Farmácia da Universidade Federal de Pernambuco. O extrato puro apresenta concentração de $0,86 \mathrm{~g} \mathrm{~mL}^{-1}$.

\section{Amostras bacterianas}

Foram utilizados vinte isolados biológicos de S. aureus obtidos a partir de pacientes internados no Hospital Universitário Lauro Wanderley da Universidade Federal da Paraíba. Estes foram caracterizados fenotipicamente como sensíveis e resistentes a meticilina e duas cepas padrões de $S$. aureus ATCC 6538 e a 33591 utilizadas como controle de referência em todos os experimentos realizados.

\section{Determinação da Atividade Antimicrobiana do Extrato da Lippia sidoides Cham.}

A atividade antimicrobiana do extrato de Lippia sidoide Cham. foi analisada pelo método de difusão em placas de Petri contendo Agar Muller Hinton. Para a determinação da Concentração Inibitória Mínima (CIM) os isolados de bactérias foram cultivados em caldo nutritivo $\mathrm{BHI}$ - Brain Heart Infusion (DIFCO); a $37^{\circ} \mathrm{C}$ por período de $18-24$ horas. A partir desse cultivo foram realizadas diluições $10^{-2} \mathrm{em}$ caldo nutritivo e estes foram semeados em Agar Mueller Hinton (DIFCO) por inundação. Foram realizadas perfurações no meio de cultura de aproximadamente $6 \mathrm{~mm}$ de diâmetro e nestas foram colocadas $50 \mu \mathrm{L}$ da solução do extrato diluída em água destilada, variando a diluição de $1: 1$ até $1: 512$. As placas foram incubadas a $37^{\circ} \mathrm{C}$ por 24 horas. Foi considerada como CIM a menor concentração do extrato que inibiu completamente o crescimento bacteriano, observada pela presença do halo de inibição.

Rev. Bras. PI. Med., Botucatu, v.12, n.4, p.452-455, 2010. 


\section{RESULTADO}

Neste trabalho, todos os isolados de $S$. aureus ensaiados foram sensíveis ao extrato da Lippia sidoides Cham. Ainibição do crescimento apresentouse homogênea, de acordo com a concentração do extrato da planta em estudo.

A CIM observada pela formação dos halos de inibição ocorreu até a diluição de 1:16 variando de 9 a $27 \mathrm{~mm}$ de diâmetro. Dos 20 isolados de S.aureus testadas, $1(5 \%)$ apresentou halos de inibição até a diluição de $1: 16\left(0,053 \mathrm{~g} \mathrm{~mL}^{-1}\right) ; 4(20 \%)$ apresentaram halos de inibição até a diluição de 1:8 $\left(0,107 \mathrm{~g} \mathrm{~mL}^{-1}\right)$; $6(30 \%)$ apresentaram halos de inibição até a diluição de $1: 4\left(0,21 \mathrm{~g} \mathrm{~mL}^{-1}\right) ; 3(15 \%)$ até a diluição de $1: 2$ $\left(0,43 \mathrm{~g} \mathrm{~mL}^{-1}\right)$ e $6(30 \%)$ apresentaram halo de inibição apenas com o extrato puro $\left(0,86 \mathrm{~g} \mathrm{~mL}^{-1}\right)$.

$\mathrm{Na}$ Figura 1 observam-se os halos de inibição do extrato da Lippia sidoides Cham. sobre o isolado de Staphylococcus aureus $125 \mathrm{H}$.

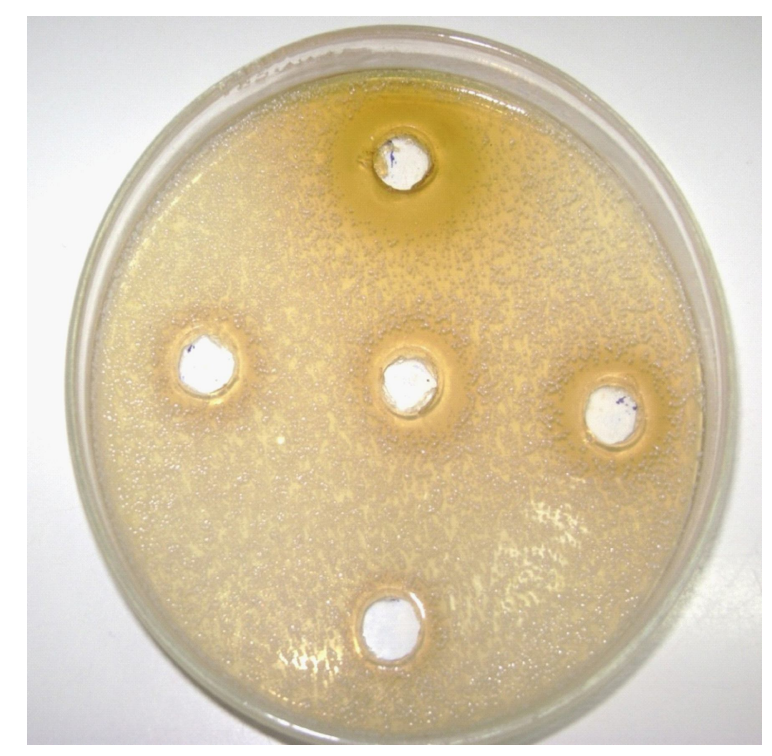

FIGURA 1. Atividade do extrato da Lippia sidoides Cham. sobre o isolado de Staphylococcus aureus $125 \mathrm{H}$.

\section{DISCUSSÃO}

O uso abusivo e indiscriminado de antimicrobianos tem proporcionado o surgimento de resistência dos microrganismos aos fármacos de uso corrente e, como conseqüência, a necessidade de se pesquisar novos produtos que possam substituir aqueles que já não têm eficácia (Masurani \& Tavares, 2007).

A resistência bacteriana aos antimicrobianos é considerada como um problema inerente à terapia antimicrobiana, por este motivo é preciso sempre buscar novas fontes terapêuticas. Testar produtos naturais pode ser uma medida alternativa importante para ajudar a resolver esse problema de resistência.
Neste estudo verificou-se a atividade antimicrobiana da Lippia sidoides Cham. (Alecrimpimenta) sobre S.aureus de origem humana hospitalar, com resultados promissores em relação a esse extrato.

Nos últimos anos vários estudos estão sendo desenvolvidos para a determinação da atividade antimicrobiana de extratos de plantas, e uma grande variedade destes extratos demonstram potencial atividade sobre um extenso número de microrganismos. Dentre esses estudos o de Albuquerque (2007) relata que o extrato da Lippia sidoides Cham. possui efeito inibitório frente a diversos microrganismo como Streptococcus mitis, $S$. sanguinis e S. mutans, S.sobrinus e Lactobacillus Caseicom formação de halos de inibição variando de 14 a $23 \mathrm{~mm}$

Oliveira et al. (2006) avaliaram a atividade do óleo essencial da Lippia sidoides Cham. na inibição do crescimento de cepas de Staphylococcus aureus observando halos de inibição do crescimento bacteriano entre $15-21 \mathrm{~mm}$.

Botelho et al. (2007) avaliaram a atividade antibacteriana e antifúngica do óleo essencial da Lippia sidoides Cham. sobre microrganismos da cavidade bucal e os resultados mostraram atividade antimicrobiana frente Steptococcus mutans, S. mitis, S.salivaris, S.sanguise Candida albicans, com halos de inibição entre 8,5 e $34 \mathrm{~mm}$.

Os produtos naturais são uma alternativa viável, uma vez que sempre foram importantes para o encontro de novas drogas. Atualmente um quarto da metade de todos os fármacos comercializados é originário de plantas, porém nenhum destes é utilizado como antimicrobiano, a grande maioria é usada como suplementos vitamínicos e dietéticos (Cowan, 1999).

Os resultados obtidos nas condições deste estudo mostram que o extrato da Lippia sidoides Cham. possui potencial antimicrobiano contra Staphylococcus aureus, o que pode permitir futuramente estudos de toxicidade in vitro e in vivo, bem como testes clínicos para posterior utilização como antimicrobiano.

\section{REFERÊNCIA}

ALBUQUERQUE, A.C.L. Efeito antimicrobiano dos extratos da Matricaria recutia Linn. e Lippia sidoides Cham. sobre microrganismos do biofilme dental. 2007. 120p. Dissertação (Mestrado - Área de concentração em Diagnóstico Bucal) - Universidade Federal da Paraíba, João Pessoa.

BOTELHO, M.A. Antimicrobial activity of the essential oil from Lippia sidoides, carvacrol and thymol against oral pathogens. Brazilian Journal of Medical and Biological Research, v.40, n.3, p.349-56, 2007.

BROOKS, G.F. et al. Os estafilococos. In: BROOKS, G.F. 
et al. Microbiologia médica. 21.ed. Salvador: Guanabara Koogan, 2000. p.157-62.

CASSETTARI, V.C.; STRABELLI, T.; MEDEIROS, E.A.S. Staphylococcus aureus bacteremia: what is the impact of oxacillin resistance on mortality? Brazilian Journal Infection Disease, v.9, n.1, p.70-6, 2005.

COWAN, M.M. Plants products as antimicrobial agents. Clinical Microbiology Review, v.12, n.4, p.564-82, 1999. HARVEY, J.; GILMOUR, A. Isolation and characterization of Stpahylococcus from goats milk produced in Northern Ireland. Letters In Aplied Microbiology, v.7, p. 140-4, 2005. LACOSTE, E. et al. Antiseptic properties of essential oil of Lippia sidoides Cham.: application to the cutaneous microflora. Annales Pharmaceutiques Françaises, v.54, p.228-30, 1996.

LEMOS, T.L.G. et al. Antimicrobial activity of essential oils of Brazilian plants Phytotherapy Research, v.4, n.2, p.824, 1990.

LORENZI, H.; MATOS, F.J.A. Plantas medicinais no

Brasil: nativas e exóticas. Nova Odessa: Instituto Plantarum, 2002. 512p.

MARTINS, E.R. et al. Plantas medicinais. Viçosa: UFV, 2000. 220p.

MATOS, F.J.A.; OLIVEIRA, F. Lippia sidoides Cham. farmacognosia, química e farmacologia. Revista Brasileira de Farmacognosia, v.79, p.84-7, 1998.

MATOS, F.J.A. Farmácia viva: sistema de utilização de plantas medicinais projetado para pequenas comunidades. 4.ed. Fortaleza: Editora UFC, 2002. 267p.
MATOS, F.J.A. Plantas medicinais: guia de seleção e emprego de plantas usadas em fitoterapia no nordeste do Brasil. Fortaleza: UFC, 2000. 344p.

MASURANI, A.; TAVARES, L.C. Estudos de QSAR-3D em derivados 5-nitro-2-tiofilidênicos com atividade frente a Staphylococcus aureus multi-resistente. Revista Brasileira de Ciências Farmacêuticas, v.43, n.2, p.10116, 2007.

METAN, G.; ZARAKOLU, P.; UNAL, S. Rapid detection of antibacterial resistance in emerging Gram-positive cocci. Hospitalar Infection Review, v.61, p.93-9, 2005.

NOVAIS, T.S. et al. Atividade antibacteriana em alguns extratos de vegetais do semi-árido brasileiro. Revista Brasileira de Farmacognosia, v.14, supl., p.8-11, 2003. SANTOS, A.L. et al. Staphylococcus aureus: visitando uma cepa de importância hospitalar. Jornal Brasileiro de Patologia Médica Laboratorial, v.43, n.6, p.413-23, 2007.

OLIVEIRA, F.P. et al. Effectiveness of Lippia sidoides Cham (Verbenaceae) essential oil in inhibiting the growth of Staphylococcus aureus strains isolated from clinical material. Review Brasilian Farmacognosy, v.16, n.4, p.510-6, 2006.

TORTORA, G.J.; FUNKE, B.R.; CASE, C.L. Microbiologia. 6.ed. Porto Alegre: Artmed, 2003. 827p.

VANDENBERGH, M.F.Q.; VERBRUGH, H.A. Carriage of Staphylococcus aureus: epidemiology and clinical relevance. Journal of Laboratory and Clinical Medicine, v.133, p.525-34, 1999. 